\title{
Prevalence of Pain Related to Schoolbag CARRIAGE IN AdOLESCENTS
}

'This study was completed in partial fulfillment of the BphysT degree, University of Pretoria

\begin{abstract}
Study design: A descriptive qualitative and quantitative cross sectional study design was chosen.

Objective: To investigate the prevalence of lower back, neck, and shoulder pain in 13 to 15 year old scholars in Pretoria, South Africa, and how it related to methods of school bag carriage and perceived weight of school bags.
\end{abstract}

\section{WADEE $F^{\prime}$, BARKER $C^{2}$, LEA $M^{2}$, EISENBERG $M^{2}$}

University of Pretoria

${ }^{2}$ Lecturer, University of Pretoria

Summary of background data: Unilateral loading has been linked to scoliotic type curves in the adolescent spine. More recent studies have also found that the weight of school bags may be related to the experience of pain, but very little research has been done on the prevalence of this pain.

Methods and materials: A stratified random sample of nine schools was drawn from a total of 98 schools in the Pretoria District of the Gauteng Department of Education. The sample of 250 Grade 8 and 9 scholars was randomly selected. A questionnaire of open and closed ended questions was administered with five main sections, namely: demographics, method of carrying school bag, perceived school bag weight, areas of experienced pain, and awareness of adverse postural effects of carrying a school bag.

Results: Thirty two percent of the sample reported pain either in the lower back, neck and/or shoulders. Principle Component Analysis and Chi-square tests showed no relationship between how the school bag was carried (over one/two shoulders; in one hand; swopping sides) and scholars' reports of pain. A high level of significance $(0.001<p<0.042)$ was found when perceived bag weight was compared to the scholars' reports of pain.

Conclusion: Scholars in the Pretoria area present with a $32 \%$ prevalence of pain in the lower back, neck and/or shoulders. This is strongly correlated with the perceived weight of their school bags, regardless of how the school bag is carried.

KEY WORDS: ADOLESCENTS; PAIN; SCHOOL BAGS; SCHOLARS. 